\title{
Karine Benac-Giroux, Destouches. Masques et métamorphoses du moi
}

\section{Paola Martinuzzi}

\section{(2) OpenEdition}

1 Journals

\section{Edizione digitale}

URL: http://journals.openedition.org/studifrancesi/3736

DOI: $10.4000 /$ studifrancesi.3736

ISSN: 2421-5856

\section{Editore}

Rosenberg \& Sellier

\section{Edizione cartacea}

Data di pubblicazione: 1 décembre 2012

Paginazione: $566-567$

ISSN: 0039-2944

\section{Notizia bibliografica digitale}

Paola Martinuzzi, «Karine Benac-Giroux, Destouches. Masques et métamorphoses du moi», Studi

Francesi [Online], 168 (LVI | III) | 2012, online dal 30 novembre 2015, consultato il 07 mars 2021. URL: http://journals.openedition.org/studifrancesi/3736 ; DOI: https://doi.org/10.4000/studifrancesi.3736

Questo documento è stato generato automaticamente il 7 mars 2021.

\section{(c) (†) $\ominus$}

Studi Francesi è distribuita con Licenza Creative Commons Attribuzione - Non commerciale - Non opere derivate 4.0 Internazionale. 


\title{
Karine Benac-Giroux, Destouches. Masques et métamorphoses du moi
}

\author{
Paola Martinuzzi
}

\section{NOTIZIA}

KARINE BENAC-GIROUX, Destouches. Masques et métamorphoses du moi, Rennes, Presses

Universitaires de Rennes (Collection «Interférences»), 2011, pp. 339.

1 Di Philippe Néricault Destouches (1680-1754), noto soprattutto per le sue due opere considerate maggiori: Le Philosophe marié (1727) e Le Glorieux (1732), ma quasi dimenticato, Karine Benac-Giroux esplora e ampiamente analizza ben ventidue opere della vasta produzione drammaturgica, rappresentate tutte, ad eccezione del Mariage de Ragonde et de Colin ou la veillée de village (Cour de Sceaux, 1714) e degli Amours de Ragonde (Opéra, 1742), alla Comédie Française, tra il 1710 e il 1764.

2 Più vicino a Marivaux che a Molière, come spiega la saggista attraverso una ricca rete di riferimenti, Destouches andrebbe oggi ridefinito e sottratto all'univoca e antica interpretazione che vede in lui soprattutto il creatore della «comédie morale»o «moralisante», trascurando la complessità dei tratteggi psicologici che caratterizza $\mathrm{i}$ suoi personaggi. Senza allontanarsi molto dal quadro e dal linguaggio della commedia molieresca, la sua riflessione etica si colloca infatti nella modernità dei Lumi, rivelando un'alleanza fra la morale tradizionale e una forma di libertà fondata sui sentimenti naturali, come sarà nel dramma borghese, con Diderot.

«Comédie de caractère mais aussi de mœurs, l'œuvre dramaturgique de Destouches est à situer dans le cadre général d'une redéfinition de la comédie du XVIII ${ }^{\mathrm{e}}$ siècle où les larmes trouvent désormais leur place», scrive l'Autrice del libro (p.12). Come già in Marivaux, il personaggio, cessando di essere il "tipo" della commedia d'intreccio, acquista in Destouches una individualità propria e uno statuto sociale. Con i suoi conflitti interiori, talora insolubili, pur conservando l'antica maschera, la commedia di Destouches oscilla fra due poli: uno costituito dal soggetto fisso, prigioniero del suo 
ruolo, l'altro, da un soggetto empirico dall'Io mobile ed instabile, che concilia in sé ragione, immaginazione e sensibilità. "L'incertitude des personnages au caractère "fixe"» è il titolo della prima parte del saggio, dedicata a queste tematiche, riproposte anche negli altri capitoli e nello studio delle singole opere.

L'ambivalenza dei personaggi è ben visibile nel Philosophe marié e nell'Envieux ou la critique $d u$ Philosophe marié, due commedie antagoniste e nello stesso tempo complementari. E opere all'apparenza molto fedeli alla tipizzazione molieriana, come Le Curieux Impertinent, Le Médisant, L'Ingrat, presentano un nuovo tratteggio delle passioni, che escono dal dominio dell'irrazionale, si riabilitano, risentono della filosofia empirica, si "naturalizzano", danno all'opera un nuovo tratteggio, quasi sperimentale, e il riso si attenua fino a sfiorare, talora, la tragedia. Ne è prova la tragicommedia L'Ambitieux et l'Indiscrète, rappresentata senza molto successo nel 1737, opera che risente della drammaturgia di Corneille e alla quale dedica un'ampia prefazione lo stesso autore. La saggista, nell'esame delle opere, procede con un attento e meticoloso dettaglio delle situazioni, degli intrecci e dei caratteri, dedicando interi capitoli alle singole opere.

Un posto particolare, in Destouches, hanno le protagoniste femminili, come la Lisette del Glorieux, opera rappresentata con successo nel 1732. Questo personaggio incarna «plusieurs identités dramatiques». Con le sue metamorfosi, dà un chiaro segnale dell'evoluzione che il teatro di Destouches sta realizzando, in sintonia con i tempi. Al protagonismo femminile è dedicata tutta la seconda parte del volume. Sia che la donna agisca per il recupero morale del personaggio maschile, come la Julie del Dissipateur (1753), opera che ci rimanda a Regnard e alla Mostellaria di Plauto; sia che operi in nome della propria libertà, come nella marivaudiana Fausse Agnès (1759) o nella Force du naturel (1750), la donna è un personaggio centrale nella drammaturgia di Destouches.

6 La terza parte del saggio: «Le sujet qui se corrige: manipulation et métathéâtralité au service de la guérison des personnages?» pone un significativo punto di domanda sul motivo nodale dibattuto dalla critica che vede in Destouches un moralizzatore. Basti citare L'Amour usé, opera nella quale «la proclamation par Destouches de la veine morale demeure pur projet» (p. 243), resta cioè allo stato progettuale.

Nella quarta parte, "Philosophie et quête de soi» viene analizzata la triade che Destouches dedica ai filosofi. Anche questi protagonisti hanno un io diviso e proteiforme. Nel Philosophe amoureux, il personaggio non sa conciliare il sentimento amoroso e l'amore della solitudine e della scienza, né il «moi» e la «morale». Nel Philosophe marié (1727), affiora la forza dei sentimenti, nella «compassion». Nell'Homme singulier (1764), Destouches, come dice nel suo Avertissement, ha l'intento di creare un personaggio opposto a quello del Misanthrope; anche se il personaggio di Sanspair non lo realizza appieno. 